\title{
EMPLOYER BRANDING THROUGH SOCIAL NETWORKING SITES
}

\author{
AJINKYA AMBATKAR \\ Symbiosis Institute of Business Management Pune Symbiosis International (Deemed \\ University), Pune, India \\ *Corresponding Authors: E Mail: Ajinkya.ambatkar.mba22@simbpune.edu.in \\ Received $19^{\text {th }}$ May 2021; Revised $4^{\text {th }}$ June 2021; Accepted $9^{\text {th }}$ July 2021; Available online $25^{\text {th }}$ Sept. 2021 \\ https://doi.org/10.31032/IJBPAS/2021/10.9.1017
}

\begin{abstract}
Visible brands depict tales of success and efficiency precisely. Companies with a strong Employer Brand capture the essence of who they are and what they are like as an employer. When you have a strong Employer Brand, your employees are your best recruiters not only because they tell great stories about your organization through the power of word of mouth, but because they also embody your company's unique spirit and value-set. They themselves become a walking talking Talent Magnet who attracts the other potential talented individuals to work with. They become brand and culture strengthening forces, because they bring in people who resonate with your organization's vision, values, and culture. The social media is an upcoming surge in the current dynamic Market scenario where we come across organizations increasing visibility on the World Wide Web through online marketing, providing unique services to their customers and trying to tap the untapped portion of the population. They have realized that social networking is the current trend and is absorbs the maximum time of the current generation. The study conducted on the effect of Social Media on Employer Brand clearly shows that there is a significant increase of presence in the area of social media landscape. The companies have inculcated the brand management strategy in the corporate policies to ensure that there is a proper fit with the changing times. There are companies that select the areas of strength that they want to tell it out to the people to fill up the candidate pool with the best talent available. The present and potential employees have certain factors that influence them to prefer one employer over another. There are also some qualities that make the brand attractive and create a better recall.
\end{abstract}

Keywords: Social Media, Employer Branding, Dynamic market, Visibility, Talent pool 


\section{INTRODUCTION}

Employer branding has been a very popular concept with HR professionals, branding consultants, and market researchers in the recent past.

Employer brand depicts an organization's reputation as an employer. As the branding of products, employer brand is widely acclaimed as one of the areas to strategies while working in the Global arena. Minchin ton defines employer brand as the image of an organization as a ,great place to work ${ }^{e e}$. It is the firm's effort to promote, both within and outside the firm, a clear view of what makes it different and desirable as an employer for the working population and appeal to them.

Accordingly to Richard Mosley, the critical aspect is to have consistency between your internal employer brand and external employer brand.

A company is challenged to develop a consistent external and internal EB that convince potential and existing employees to work with a specific organization.

Employer brand comes handy while dealing with two kinds of people

a) The Future employees- Why should I work for this company and not the competitors

b) The Current employees- Why should

I be loyal to this company and feel proud to do so.

To get a positive response for both questions, a company needs to put in line an effective brand management strategy that is consistent with the overall policies of the company. Without a match between the external and internal policies the voice of employer brand will be distorted. The clear measure of a better employer brand would be the ratio of number of offers given to people to the number of people who finally joined. The recruitment costs and time will come down as the organization becomes more lucrative to join and lesser effort is needed to recruit people. In the long term the right brand will definitely help people stay and the reasons will be more than monetary considerations. Being an employee is an integral aspect of the strategy formulation, it encompasses every aspect of the employment experience, to mould the perceptions of present and potential employees. To sum up, brand is not just its outward appearance but the sum of all activities that supports both external and internal image.

The key aspect of employer branding is to understand that it is not just about advertisements or communication collaterals it is the reflection of what is the reality present or future that the employees experience in the organization.

\section{Employer brand proposition}

Employer Brand proposition is essential for effective Employer Brand Management. 
This highlights the attributes that differentiate it from other employers. This also includes the ,psychological contract ${ }^{\text {ee }}$ which tells what the company is expected to do for the employees and what is expected out of employees.

\section{Internal Marketing and Employer}

\section{Branding}

Internal Marketing aims at delivering the message of customer brand promise and attitudes and behaviors expected from the employees to deliver on that promise. It helps in clearly understanding the role of employees towards the customers. But however it is said that the role of internal marketing is short-lived because if the brand values on which the service experience is founded are not experienced by employees in their interactions with the organization they are working in .This gap is successfully filled in by the concept of employer branding which helps in practicing and seeking to address with a more mutually beneficial employment deal.

\section{Brand-led culture change}

While brand-led culture change is often the stated desire of these programmes their focus on communication-led, marketing methods (however, involving or experiential) has been prone to the same failings of conventional internal marketing. As Amazon 's founder, Jeff Bozos asserts: "One of things you find in companies is that once a culture is formed it takes nuclear weaponry to change it".

In short, every company puts in efforts to tell the present and prospective employees why they should work for them and not their competitors.

\section{Employer Branding - Its relationship with}

\section{HR}

As of now we saw how the concept of employer branding relates to different management fields, now however we would come over to its contribution and effect in terms of the area of Human resource management. The employer brand approach can potentially help to address two of the key challenges at the heart of HR management. As Dave Ulrich pointed out in "Human Resource Champions", the first of these is HR's requirement to be both a partner to the business and employee champion.

The tools of brand management are designed to address this balancing act by helping to define and mediate between the value of the brand to people and to the business. It's generally in the customer's interest to demand more for less. It, s generally in the business ${ }^{\text {ee }}$ interest to offer less for more. If this sounds familiar in the context of employee pay negotiations, we believe there is a distinct benefit in extending this conscious and explicit balancing act to the broader relationship (the "psychological contract") between the employee and the organization. The second 
challenge is the requirement for $\mathrm{HR}$ to be both agents of change and guardians of stability. As Ulrich points out: "Businesses must balance the past and the future...the benefits of free agency and control...efficiency and innovation". This second balancing act is also a central feature of effective brand management, and we believe that the well-honed tools associated with this discipline can be of great benefit to the HR profession in addressing this complex and highly demanding task.

A further major benefit of adopting the employer brand approach is the scope it provides for more seamless integration with the ,external ${ }^{\text {ee }}$ business agenda. Adopting a ,joined- up ${ }^{\text {ee }}$ model of internal and external brand relationship management can help to clarify and resolve many of these apparent conflicts and ensure that both the internal and external agendas can be brought together efficiently.

Any activity that an organization undertakes influences the people's perception of the employer brand and the employment experience. It helps the organization in identifying its position in the market as a present and potential employer and as having a good relationship with the customers.

The three major benefits of strengthening employer brand identified in separate studies
Conducted by Hewitt Associates, The Conference Board and the Economist are cited as being:

- Enhanced attraction

- Retention

- $\quad$ Engagement

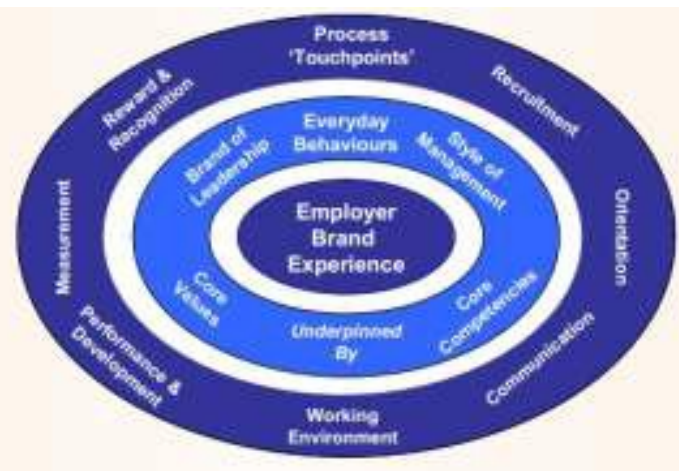

Figure 1: Employer Brand - The total Journey

\section{Problem Statement}

The project aims at collecting the data about how the current, prospective and exemployees think about the presence of the company in the social front. This will allow seeing, what are the areas of social presence that impacts the employers ${ }^{\text {ee }}$ brand the most. And also what are the characteristics of the employment experience that should be present in the company brand and what are the characteristics of the brand that influence the employees the most. The project aims at finding out what are the areas that make the brand what it is today.

\section{Objectives of the study}

1. To analyze how effectively social media can be leveraged to create and maintain positive employer brand.

2. To measure the awareness of the 
concept of employer brand.

3. To analyze if brand Image influences culture of the organization.

4. To find what aspects of employer brand influences individuals.

5. To measure the importance of employer branding on employees of the organization

\section{Literature Review}

Many articles were read and reviewed to get background knowledge about the study. They are listed as follows:

In a research pursued by Branham (2001), the author highlights the concept of the employer brand, adapted from marketing theory, which has increasingly become the focus of organizations towards developing their image as an employer of choice, thereby effecting human resource management by enabling the recruitment and retention of the best possible workforce. Acquiring, keeping and engaging these value-adding employees has seen many firms working harder at promoting themselves as desirable employers to potential and current employees. Employer branding programs include regular job training, training in customer service or customer interaction, corporate orientation, and education in the corporate brand. Well developed employer branding programs also include ongoing training, performance evaluation and rewards systems that support the

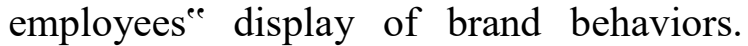
The paper presents conceptual framework of employer branding with employer branding as an archetype to attract talented employees. It further focused on employing strategies to attract endowed employees "Both sides now": aligning external and internal branding for a socially responsible era John Aydon Simmons In this article the author talks about aligning the internal and external branding through marketing strategy and demonstrates the benefits of viewing both synergistically in relation to value propositions offered to stakeholder groups and the beneficial outcomes that can result from it. The facts found include The significance and application potential of a conceptual framework that analyses relationship between the brand benefits and values that an organization espouses; The conclusions of the paper shows particular significance for service brands where successful customer organization relations are dependent on staff commitment that is itself predicated on organization concern for employee well being; The paper presents a business based rationale for the marketing function to recognize greater stakeholder concern - especially that of customers and employees - for ethical marketing and sustainability; and the financial, social and ethical capital benefits that can accrue from responding to this. 
In The study of Cable and Turban's (2001), the author explains an employer knowledge framework .It applies marketing concepts to recruitment research literature in order to develop the concept of employer knowledge, or the beliefs that a job seeker holds to a potential employer. Job seekers employer knowledge creates value of an organization because it determines how they pursue and process information about the organization whether they accept jobs, what they expect and whether they purchase products and services of the organization .The model illustrates implications for recruitment, research and managers and suggests new perspectives and research directions that emerge from marketing and recruiting literatures.

The study of Backhaus and Tikoo (2004), who are often viewed to be the first authors to acknowledge a change in branding in relation to HRM and state that employer branding is based on the assumption that human capital brings value to the organization. The employer branding is seen as a three leg process in which [1] the value proposition of an employer brand is developed, [2] the employer brand is marketed external, and [3] the employer brand is marketed internal and becomes a part of the organizational culture. Employer branding in this study is defined as the process of developing and communicating organizational information that is specific and enduring for a firm as an employer and differentiates it from its competitors (Backhaus \& Tikoo, 2004).

The prime purpose of the study of Davies 2008 was to investigate whether employers use branding in their organizations, and how employer branding influence the attraction and retention of employees in the banking sector in Ghana. The results of the study suggest that organizations use employer branding processes in their business to attract employees and customers. It was also found that brand names of organizations may significantly influence the decision of employees to join and stay in the organization. It was therefore suggested that employers need to create conducive work environment with conditions to enable employees feel comfortable and remain in the organization.

Michaels et al \& Ewing et al. 2002 propose the explicit development and communication of employee value proposition (EVP) to attract and retain talented employee. Recruiting right type of talent becomes critical, as does the employer brand image in the recruitment market.

The paper of Knox \& Freeman states that in competitive labour markets, the challenge for service-based organizations is differentiation to attract and retain talented staff. The notion of Branding the firm to potential and existing employees has been 
evoked in the marketing literature .The paper measures through empirical study the aspects of this "employer brand" image among potential recruits and recruiters during the recruitment process. The managerial implications of developing a more consistent employer brand image in the recruitment market are discussed.

The paper of Barber 1998 highlights that brand image affects the job search behavior of employees /individuals, but the result is undetermined. The paper further proposes that job applicants apply to a job vacancy seeking to organizational attributes primarily as a predictor and brand image secondarily as a mediator. Further the paper suggests directions for practitioners concerning recruitment efficacy.

The purpose of the paper Aaker 1991 is to discuss and elaborate the main issues encountered in managing brand equity. The paper analyses the concept of brand equity; and then provide a comprehensive framework for managing brand equity; and finally, distinguish different ways to leverage and measure brand equity. The concept of brand equity emerged in the early 1990s and can be regarded as a managerial concept, as a financial intangible asset, as a relationship concept or as a customer-based concept from the perspective of the individual consumer.

The paper of Berry \& Parasuraman tests a general framework for building customer- brand relationship from an experiential view, which aims to describe the extent to which customer intention to repurchase a brand is influenced by brand relationship quality (brand satisfaction, trust, and commitment), service quality and brand experiences.

The research findings indicate that brand experience appears to be far more salient than brand constructs in shaping and building meaningful and long-lasting relationship with consumers.

The paper of Filip Lievens, Greet Van Hoye and Bert Schreurs finds some evidence of interactions between the three dimensions job, organizational attributes \& employer familiarity. Specifically, trait inferences and job and organizational attributes had more pronounced effects when familiarity was high. From a theoretical perspective, these results supported the framework of employer knowledge. At a practical level, implications for image audit and image management are discussed.

The purpose of the paper Branding in sustainable organizations - Helle Kryger Aggerholm, Sophie Esmann Andersen and Christa Thomsen Centre for Corporate Communication is to reconceptualise employer branding in sustainable organizations at the intersection of branding, strategic human resource management (HRM) and corporate social 
responsibility (CSR). The facts found include: When organizations adapt sustainable development including social CSR activities, It effects how to approach stakeholder relations and organizational processes including employer employee relations and current employer branding processes. The paper conceptualizes branding as an integral part of CSR strategy thus offering a new way of approaching employer branding as supporting sustainable organizational development and developing long term employee employer relationship.

Ecnomic Times: An effective brand image, when projected correctly, does not only communicate the corporate details like size and profits of the company but also its values, behaviours and policies. Therefore, its necessary to project the correct image and it turn means to choose the social media options correctly.

Economic Times once published an article about the brand image of Google and wrote: "Due to Google's remarkable brand image, students worldwide see it as a company they would like to work for."

All over the world, people of all demographics have appreciated and accepted the presence of social media. Today, social media has provided a platform for everyone to tell their story. This has led to a transformation in the way things are nowadays. Even the business strategies have seen changes in the strategies. The strategies like recruitment and staffing have evolved to lose total dependency on traditional methods and involve new ways to attract and retain talent. One of the factors that directly and indirectly affect the people who are attracted towards a company is Employer Brand.

According to an article published by Society of Human resources "An effective employer brand is essential for competitive advantage. Increasingly, Indian corporations are becoming intentionally strategic to utilize the employer brand to attract and retain talent and, ultimately, to expand and grow." The article also says that- "The increasing focus on competitive advantage is leading many firms to rethink their employer brand."

The paper of Biedenbach 2012 entitled "Brand equity in the business-to-business context: Examining the structural composition" (Biedenbach 2012) investigates the structural composition of brand equity and the interrelationships between the dimensions of brand equity in the B2B context. By specifying the multidimensional model, which can be utilized for measuring and managing B2B brand equity, the paper provides initial knowledge on how the companies can build a strong B2B brand across four dimensions of brand equity. 
The paper of Biedenbach 2010 entitled "B2B brand equity": the impact of contextual factors" examines the impact of contextual factors in the organizational decision making process on the formation of $\mathrm{B} 2 \mathrm{~B}$ brand equity. The book chapter expands knowledge on B2B brand building by portraying how such characteristics of customers as relative size of their company and its industry sector can affect B2B brand building.

Biedenbach and Marell 2010 titled "The impact of customer experience on brand equity in a business-to- business services setting" (Biedenbach and Marell 2010) investigate the impact of customer experience on brand equity in the professional services setting. The study shows that customer experience has significant positive effects on brand awareness, brand associations, perceived quality, and brand loyalty. The study clarifies how customer experience can be utilized for building a strong B2B brand.

Biedenbach, Bengtsson, and Wincent 2011 titled "Brand equity in the professional service context: Analyzing the impact of employee role behavior and customer-employee rapport" (Biedenbach, Bengtsson, and Wincent 2011) examines whether factors related to customers ${ }^{\text {ee }}$ perception of employees ${ }^{\text {ee }}$ role behavior in terms of customer perceived role ambiguity, role overload, and customer- employee rapport influence the development of brand equity in the professional service context. The paper advances knowledge on B2B brand building by Considering the potential role of the company employees and consequences that their behavior can lead to in this process.

Taylor, Hunter \& Lindberg 2007 made a study which provides marketing managers with clear understanding of how customer experience can affect the development of brand equity in the B2B setting. The study motivates marketing managers to integrate the efforts aimed at enhancing brand equity and creating customer experience.

The main question here is to know what the level of impact social media has on the Employer brand so that the companies can utilize the option correctly and to the maximum use. The report also discusses the factors that affect the propagation of the employers brand among the present and potential employees.

According to Brett Minchington "Due to its potential size, scope and scale, social media has become appealing to businesses of all sizes around the world. Successful use of social media has a positive impact on employer brand"

The paper of Mittal \& Kamakura seeks to explore the role of the employer brand in influencing employees perceived differentiation, affinity, satisfaction and 
loyalty

- four outcomes chosen as relevant to the employer brand.

The findings emphasize the importance of an employer brand but the Results also highlight the complexity in its management, as no one aspect has Outline of the current knowledge and approach of this research paper:

Despite employer brand gaining considerable popularity in HR practitioner literature (e.g., Frook 2001) empirical research is still relatively inadequate (Cable \& Turban 2001). Backhaus \& Tikoo (2004) and Davies (2007) echo the same sentiments and feel that the advent of the employer brand as concept has been recent in academic field and its theoretical foundation is gradually being developed even though it is being considered and applied by practitioners for some time now.

Michaels et al. (2001) propose the explicit development and communication of employee value proposition (EVP) to attract and retain talented employee. Recruiting right type of talent becomes critical, as does the employer brand image in the recruitment market (Ewing et al., 2002).

Research studies in the area looking for continued association of these employees in particular are scarce as most of them focus on potential applicants.

"This research captures the employer brand image of the current employees and its consequences"

Although the study of organizational attraction has revealed some insights, there remains much to be learned according to the paper (Barber 1998). One stream of resdorahnant imflestigatos outcongressizaltéonat to the employ characteristics and their effects on attraction to the organization. Structural attributes such as decentralised decision making (Turban \& Keon 1993) and reward system (Bretz et al, 1989), are shown to influence perceptions of attractiveness. Gatewood et al. (1993) found that perception of an organisation's image is a significant predictor of decisions to pursue employment with that company. Using brand in the context of employment, employer brand loyalty was found by many to be a useful concept to be applied. Brand loyalty is the attachment that a consumer has to a brand (Aaker 1991). Applied in the context of employment, employer brand loyalty is shaped by behavioural element relating to organisational culture and attitudinal element relating to organisational identity (Backhaus \& Tikoo 2004). But unlike in the case of a product, in employment brand loyalty switching over to another brand cannot be done so frequently and comes at higher cost (Davies 2008). In a way employer brand loyalty forges greater commitment level resulting in increased retention of the talent. One role 
of brand is to create and enhance satisfaction and satisfaction predicts future behaviour towards the brand (Mittal \& Kamakura 2001). Job seekers learn about job openings through a wide array of sources such as advertising, websites, and job fairs. Although the effectiveness of these recruitment sources is one of the most intensely researched aspects of recruitment, the focus has been on post-hire instead of pre-hire outcomes (Barber, 1998). The employer brand is the package of psychological, economic, and functional benefits provided by employment and identified with an employer (Thorne, 2004). Manipulating these benefits to position the firm in the minds of potential employees as a great place to work (an employer of choice) is the role of employer branding (Branham, 2001). Closely related to employer branding is internal marketing, which considers the company to act both on consumer and employee markets (e.g. Papasolomou-Doukakis, 2003). The basic tenet of the internal marketing approach is that good customer service is only possible if employee satisfaction and motivation are high (e.g. Berry \& Parasuraman, 1992). Consequently, internal marketing suggests that jobs are managed in a similar manner to products, and that the company should use marketing techniques to design jobs to meet both the employeese ${ }^{\text {ee }}$ and the firm's needs, and to communicate the benefits of employment to internal and external markets. Creating a strong employer brand will have positive consequences for communicating these benefits. Whilst much attention has been dedicated to examining the role of branding from a customer perspective and associated customer-based brand equity (e.g. Taylor, Hunter, \& Lindberg, 2007)

Relatively little research has explored the role that branding plays in retaining and attracting employees that constitute the firm's human capital and, ultimately, contribute to the efficient and effective Brand value delivery.

"This study will concentrate on the HR perspective of the employer brand. Through this study, the area of HR will be defined on the basis of how much there is effect on employees when it comes to the social media impact and opinion of others about the company.

The Blue Print

Building the employer brand through social media

Social media has become a powerful tool for building a strong employer brand. Social recognition media allows an employer to take advantage of social networks to spread workers recognition and demonstrate why and how it can provide the best working environment. The employer brand efficiently and effectively is one that has a very small difference 
between the internal (inside the organization) and the external also for the general public image.

The truthful employer brand is an effective strategy to encourage employees to "live the brand." Previously it was restricted primarily to take advantage of the availability of employment sites for the recruitment drive. Therefore, little is known about what makes an attractive employer brand to employees, both current and potential. There may be several factors that are attractive to a brand, but not the other. There may be some aspects of an organization that can help it stand out, like, the quality of co-worker, teamwork, etc. that is often found that the specific attributes that are considered more attractive by the employees are completely different in each organization. However, the categories for judging an organization are the same in all organizations. These were employment, the success of the organization's external image and product attributes or service quality that it represents.

Des Walsh gave 9 reference points for successful development and implementation of Social Media Strategy. They are:

1. Commitment

2. Culture

3. Market

4. Goals
5. Resources

6. Listening

7. Engaging

8. Technology

9. Evaluation

1. Commitment

High level corporate commitment is a key element of a successful strategy development and implementation. Such commitment is no guarantee of itself that everything will be done well, or even that there will be no major problems encountered. But in the absence of such commitment, even the best articulated strategy may well be doomed to failure.

2. Culture

Conversations about social media in business typically start with questions about tools. "Should we have a Facebook page?" "Should we be on Twitter?" "Should we have a blog and if so how do we go about that?" These are perfectly reasonable questions. But from a strategic point of view trying to answer those questions in a vacuum is usually unproductive. Before any decisions are made about social media platforms or tools, there needs to be a serious discussion about company objectives and social media strategy. And, of course, about company culture. Because a social media strategy that doesn't fit with company culture, or is not synchronized with a strategy to change company culture if that proves necessary 
for success, is bound to fail.

It is also clear, from case studies and from anecdotes shared by social media practitioners, that the toughest challenge with social media or social media implementation is often not about platforms or tools or even about budgets, but about culture.

At the risk of over-simplification, what is meant here by corporate culture is what is sometimes described in terms of "the way we do things around here". Of course, "the way we do things" will often be

3. Market

A market scan is a next step in developing a social media strategy. Just as for any business strategy, we need to know who our customers, prospects and other stakeholders are. For a social media strategy we also need to build a picture of their actual or likely online behaviour and especially whether and how they use social networks. And as with any market investigation, it is probably a good idea to put prejudices aside and discover what facts we can about these issues.

For example, many mature age business executives might not be themselves active on social networks, and assume that social networking is not relevant for their business because they are not catering to a young demographic.

4. Goal

Many companies approach social media initially as a way to get their message out more effectively and see social media as offering, in effect, a bigger megaphone. In one way it does, but there is a lot more to the picture than that, and it is essential to get very clear about the company's objectives and goals in setting up a social media strategy. Part of that process is to keep in clear focus the fact that social media is interactive.

\section{Resources}

One of the most business-unfriendly myths about social media is that it is all free. "Won't cost anything". Just because it does not cost anything to sign up for a Twitter account, or Facebook or many other social media services does not mean by any means that there will be no cost. The reality is that it will cost!

But what one can reasonably expect is that, with a well- developed and well-executed social media strategy, one will get more value for the outlay, more impact for the spending than by depending solely on traditional ways of promoting and positioning the company. At the very least one will have to incur the cost in terms of the time spent by staff on building the company presence on the social web, responding to feedback and so on. And it gets into social media more intensively there are other costs that can reasonably be incurred.

It is also worth bearing in mind that there 
is a cost involved in not doing anything.

If one accepts that social media has changed the way one does business, then one will not have a problem in seeing that, by not taking strategic action, one can be effectively missing out on the profitability which is implicit in the new possibilities offered by social media, such as for building brand awareness, customer retention and acquisition, establishing or maintaining thought leadership, and improved internal communication and collaboration.

\section{Listening}

"Communication, whether inbound or outbound, is now powered by conversations, and the best communicators always start as the best listeners. And the best listeners are those who empathise while they are listening." Brian Solis, Engage!

The engagement online happens where people listen, not where there is just someone with a megaphone telling the public to buy their stuff. Not that one has to be everywhere on the web, constantly listening. There are tools to help and the good news is that some of them like Google Alerts are free. So one can experiment without a direct financial cost and start to learn what you really need to know and for which you might have to investigate some of the paid services currently proliferating. 7. $\quad$ Engaging
As Brian Solis put it succinctly, "Engage or die." In his excellent introduction to social media, The Digital Handshake, social media specialist Paul Chaney suggests that there are two ways to engage with social media. "One is relatively more passive joining a conversation that is already underway: the other is more proactive "starting a conversation about your company, products and people". As the author points out, it doesn't have to be either/or. illustration, one is probably more likely to attract people to own functions if they have seen one attending and supporting theirs.

8. Technology

A Facebook page might be ideal for some strategies and a non-productive time-sink for others, although given the vast number of people on Facebook we generally recommend to clients that they have some presence and engagement there.

Not every expert will agree, but our view is that every company should consider having a blog (weblog), not just a traditional, static website, as part of its presence on the social web. There is also an international dimension. For example, if the company does business in China one would be wise to learn about Renren (formerly Xiaonei) and Baidu and not assume that knowing about and being findable on Facebook or Google is enough.

Similarly, if a company is doing business in 
Brazil, it would be smart to get up to speed on the LinkedIn site, very popular around the globe.

But what would be a good basic list of platforms to consider for companies doing business exclusively or mainly in Englishspeaking countries such as the USA, Canada, the UK, Australia and India are as follows:

A suggested starter list for consideration:

- $\quad$ LinkedIn

- Facebook page

- $\quad$ Twitter

- YouTube channel

- Corporate blog

9. Evaluation

We conclude that current and potential employees tend to perceive the mark of an employer organization in different ways. The two groups tend to value different attributes. Therefore, one can say that means that the results of the investigation of the employer brand potential worker participation cannot be generalized to current employees. To determine what makes an attractive employer brand for current employees, one must select the unique perspective of people in the organization. However, this requires some understanding of how the employment relationship can change an individual assessment of the brand or the employer's organization.

\section{Findings}

Objective 1 ---- To analyze how effectively social media can be leveraged to create and maintain positive employer brand Managers:

All managers are all users of social media for the purpose of Networking and connecting to acquaintances, friends and executives in the same field as theirs.

Majority of managers access LINKEDIN, followed by BLOGGER SITES and FACEBOOK when their responses are observed.

Majority of the managers disagree that their brand awareness is created majorly through social media websites.

Employees:

All the employees are users of social media websites for the purpose of pleasure, networking with individuals working in the same field and also for the purpose of Time pass .All employees are most frequent on FACEBOOK over LinkedIn as compared to the level of managers and are less on blogging sites as compared to managers. Although the number of employees who agree that their employer branding awareness is created through social media websites is more than managers. Half of the employees in the focus group agree while the other half disagrees.

Students/Job Seekers/Job Switchers:

All students are users of social media websites for the purpose of majorly 
pleasure and timepass.2/8 students in the focus group use it for networking and half of them for blogging. However majority of the focus group of students agree that their brand awareness is created through social media websites when compared to the number of those managers and employees who agreed to it.

Objective 2 --- To measure the awareness of the concept of employer brand.

\section{Managers}

All managers are aware of the concept of employer branding.3/of the focus group members feel that functional value of employer brands influence them. $1 / 8$ feel psychological aspect of the brand influences them, while $4 / 8$ of them feel that values influence them the most.

\section{Employees:}

The number of employees aware of the concept of employer branding are lower than the number of managers $(5 / 8)$ while the rest are vaguely aware of the concept. Most employees are influenced by the economical aspect of the employer brand unlike managers. Who are mostly influenced by functional and all the other aspects mentioned of the brand. .A single individual in the employee cadre feels that all the aspects mentioned influences.

\section{Students:}

The number of students who are aware of the concept of employer branding is the same as the number of employee awareness of the focus group. Most of them are influenced by the functional and economical aspect of employer branding. While a single individual feels that psychological aspect influences him.

Objective 3 - To analyze if brand Image influences culture of the organization.

\section{Managers}

All the managers collectively felt that yes the benefits provided by the employees is relative/should be relative to the brand value social value of the organization in the market. They said that all the factors of enhanced talent attraction, retention and engagement are reason for building a strong employer branding. They all said that importance to work falls in the highest priority when it comes to the fact of fulfillment of the psychological contract of branding, followed by recognition and empowerment for the purpose of employee sustenance and engagement in the organization which are contributors to internal branding/marketing. From the attraction perspective all the managers feel that it is more advantageous to build a better potential to tap untapped talent pool while some of them also agreed that a better source to fill talent pipeline is also another perspective to it.

Students

The group of students collectively agreed to the employer branding concept being relative to the brand value/social value of 
the organization. They said that the reason for building a strong employer brand is mainly enhanced talent attraction followed by engagement and retention which are mainly for the internal harmony of the organization. While considering the feature of psychological contract, they said that a better potential to tap talented pool is more dominant over better source to fill the talent pipeline. Also the group agreed that an effective brand management strategy can very well help in internal marketing of the organization amongst its current employees pertaining to the psychological contract with the support of the policies and rules to help sustain the brand value of the organization.

Objective 4 --- To find what aspects of employer brand influences individuals.

Managers

Managers group stated that a brand name must have Connect with the external as well as internal individuals. By connect they said it contributes to the aspect of marketing. The more you feel associated with a particular brand and the more it appeals understandable to you. You would find it more convenient and easy for an organization to convince you to buy it and win more loyal customers for increasing sales. After all its about numbers to increase business. Although the other factors of relevance and simplicity are also included in the connectivity point. They all feel that employer branding is important because it sums up a companyees effort to communicate to existing and prospective staff and make the organization a desirable place to work for by shaping the perception of existing and prospective employees as it successfully fills up the known gap of internal marketing in the organization.

Employees

The employee group also agreed like the managers group that connectivity of a brand name to individuals holds more importance including simplicity and relevance. They also said that employer branding is important because it is a sum of company's effort to communicate to existing and prospective staffs as it shapes perceptions by filling up the known gap of internal marketing.

Students

Like employee and managers group the student group too agreed to the connectivity of brand names holding more importance in the market scenario followed by simplicity and relevance depending on the target customers chosen. They also said that employer branding is important because it is a sum of company's effort to communicate to existing and prospective staffs as it shapes perceptions by filling up the known gap of internal marketing.

Objective 5 --- To measure the importance of employer branding on employees of the organization. 


\section{Managers}

The managerial group said that it is indeed necessary for them to be aware of the brand value of the organization they are working with to continue doing business in their respective fields and were positive about their satisfaction levels with the brand they are working with.

Employees

Employees are aware of the brand value of the organzation they are employed in but half of them agreed to be loyal and satisfied with the brand delivery of the organziation while the other half disagreed and claimed to be unsatisfied.

\section{Students}

The students were aware of the brand value of the organization they would wish to work for. However they claimed that the market scenario doesn ${ }^{\text {ee }}$ allow all of them to be absolutely loyal in their approach and close all other options of employment when asked about brand loyalty. So most of them were flexible and said what was more important was to get a good profile with monetary benefits over being absolutely brand loyal towards a particular organization.

\section{Recommendations}

As the war for talent increases, savvy employers are learning how to capitalize on the strength of their brand in order to attract top candidates. The wider perception of an organization can impact recruitment and retention and can be used to strengthen the overall reputation. In this new era, employers will influence rather than control their brand and should actively participate in social media where they"ere being discussed.

- Have a presence. Above all, make sure you are online, or else you've already dropped the ball. "The candidate of today communicates via social media. To not have a presence would suggest that the organization is not progressive," Tiffany Quinlan, HR Director at Randstad, said.

- The responses indicate that maximum population is users of social media, Facebook topping the list followed by LinkedIn for professional purposes. These websites are free to access and creating an account is costs nothing. It also indicates that the audience captured here are much higher when compared to any other advertising websites. Hence Employer branding promotional offers and advertisements need to make their presence where there is higher mass involvements and word of mouth if they want to cater to the needs of the generation and understand their consumption pattern. 
- Take note of negative feedback.

Poor reviews or negative comments about your organization on social networking sites shouldn ${ }^{e e} t$ be disregarded - try evaluating them objectively, and seeing if there is anything you can learn.

- Respond to criticisms. The advantage of social media is that you have a voice, too. Well thoughtout responses to criticisms you receive can not only provided a weighted voice, but people will appreciate that you are being proactive.

- Use employees as ambassadors. Whether you are or not, the majority of your employees are on social media sites such as LinkedIn. By ensuring your placement on their page - either through mention in their $\mathrm{CV}$ or through advertisements - the star-power of your high- performers can help validate your organization and bolster your employer brand.

- Know your audience. Successful businesses know how to adapt their employer brand to appeal to different target audiences; taking into account different values, ambitions and cultural backgrounds. What makes a graduate tick is unlikely to excite an experienced worker in the midst of their career, so speaking the right language is key. Think about the sort of person that you're trying to attract, what they will be looking for in terms of their career, and how your company ${ }^{\text {ee }}$ vision can align with their immediate and long-term ambitions.

- Every impression counts. While a jobseeker's first impression of your organization will determine their immediate interest in you, this judgment is continually changing. Each brush with your brand influences a person's perception of you, so the process of building a favorable employer brand actually begins far earlier than the recruitment process itself.

- Address this by reviewing every encounter an individual might have with your brand - from calling your helpline as a customer, to receiving interview feedback as a jobseeker. Identify where your brand may be falling down before, during and after the application process; and work with your recruitment partner, HR department and marketing functions to create a favorable experience at every stage. 


\section{CONCLUSION}

This study provides inputs about how the various individuals perceive the concept of employer branding and how much they are influenced by it through social media in that context. It also gives an idea as to what are the qualities in the companies that are more attractive to the present and potential employees. When we talk about the various aspects of the brand image there should be a relational aspect that connects the external as well as internal image of the company.

The brand image depends on how well the employment experience is propagated among the masses. The factors that are appreciated among the brand are fulfillment of Psychological contract and Functional aspects. Psychological contracts are Empowerment, Importance of work, Recognition of performance, Sense of Achievement and Respect by seniors and colleagues. These are the things that promote the sense of belongingness in the employers. Out of these factors, the sense of achievement and the recognition of performance play an important role in attracting the employees towards the brand. For e.g.: retailers like shoppers stop display a picture of the employee of the week on the store walls. This motivates the selected employee and encourages the others to perform. The outsiders see and appreciate the gesture. Hence, the employees also strive to maintain the level of proficiency expected from them.

Social media is a common place for all the strata of the society to meet, whether we talk about the intranet within organizations or the internet, for the world, it's the era of continuous interaction and this media caters to the temporary escape which gets created when an individual is online. That is the escape vacuum which companies must aim to catch and promote them.

Therefore, it can be said that Social media provides a platform for the companies to reach out to the mass. It helps reduce the cost of recruitment, the time taken and also promotes the culture to attract and retain the best talent available. There is also a flip side to it but it gets neutralized when the advantages are higher in number. What companies need to focus on is to get the right "strategy". It should include the implication of the message to be sent across to the audience targeted and the value which would help in catering to the identified unfulfilled need.

There is a famous quote about brand and branding that says it all:

\section{"If you try to be famous for everything,} then you will be famous for nothing".

Scope for Further Study

The current research undertaken was to observe the effect on employer brand due to the popularity of social media..

There is a scope to refine the study in the 
following ways:

1. Collecting data from more respondents: more the number of respondents, more accurate deductions

2. Quantitative Analysis: The analysis carried out in my project was focus group analysis qualitatively which required more substantiation. However a quantitative method might provide higher reliable results and give a statistical approach to the study.

3. Data collected can be differentiated by Industries: This will show clear implications of the study industry wise

4. Classification on the basis of Age: To show the trend which are following up in the current.

\section{REFERENCES}

\section{Books / Chapters read / procured:}

[1] The employer brand -bringing the best of branding by Simon Barrow \& Richard Mosley (Procurements: Part 1about the rationale for change; Part 2 Brand Positioning; Part 3 -Durability of the Employer Branding concept)

[2] Forced Focus : Penny Burke (Procurements : In this excerpt from her book, Forced Focus, Penny Burke outlines how to implement an engaging workplace brand that takes the best of an organization's external brand and applies it to an internal employer brand)

Research Papers / Articles read / procured / downloaded / Databases used:
[3] Research Paper How to find out the heart of your Employer Brand: Cornell University.

[4] Journal on - The Relationship Between Early Recruitment-Related Activities and the Application Decisions of New Labour-Market Entrants: A Brand Equity Approach to Recruitment

[5] Research article - Employer branding: A new strategic dimension of Indian corporations @Asian Journal Of Management Research Online Open Access publishing platform for Management Research

[6] Emerald Group Publishing- Innov ate or Die : Why innovation is the key to business success in a changing world

[7] Branham 2001 "Both sides now": aligning external and internal branding for a socially responsible era John Aydon Simmons

[8] The study of Cable and Turban's (2001): Examining the relationship between employer knowledge dimensions and organizational attractiveness: An application in a military context.

[9] The study of Backhaus and Tikoo (2004): Employer Branding and its Effect on Organizational Attractiveness via the World WideWeb.

[10] The study of Davies 2008 Michaels et al \& Ewing et. al. 2002 : An Empirical Investigation of the Predictors of Executive Career Success

[11] The paper of Knox \& Freeman: 
Measuring and Managing Employer

Brand Image in the Service Industry.

[12] The paper of Barber 1998 : The Effects of Organizational Brand Equity on Employment Brand Equity and Recruitment Outcomes

[13] Aaker 1991 :Managing Brand Equity

[14] Berry \& Parasuraman: The Investigation And Analysis Impact Of Brand Dimensions On Services Quality And Customers Satisfaction In New Enterprises Of Iran.

[15] The paper of Filip Lievens, Greet Van Hoye and Bert Schreurs :Branding in sustainable organizations - Helle Kryger Aggerholm, Sophie Esmann Andersen and Christa Thomsen Centre for Corporate Communication.

Article published by Society of Human resources

[16] The paper of Biedenbach 2012 entitled "Brand equity in the businessto-business context: Examining the structural composition" (Biedenbach, 2012)

[17] Biedenbach 2010 entitled "B2B brand equity": the impact of contextual factors" examines the impact of contextual factors in the organizational decision making process on the formation of $\mathrm{B} 2 \mathrm{~B}$ brand equity.

[18] Biedenbach and Marell 2010 titled "The impact of customer experience on brand equity in a business- tobusiness services setting" (Biedenbach and Marell 2010)
[19] Biedenbach, Bengtsson, and Wincent 2011 titled "Brand equity in the professional service context: Analyzing the impact of employee role behavior and customeremployee rapport" (Biedenbach, Bengtsson, and Wincent2011.

[20] Taylor, Hunter \& Lindberg 2007: Brand Building in the Business-toBusiness Context: The Brand Equity Perspective

[21] Brett Minchington: Employer Branding: A new Archetype to Target Endowed Employees

[22] The paper of Mittal \&Kamakura : Employer branding and its influence on managers

[23] Emerald Group Publishing - How leaders influence Employees; How Strategy effects; Recognize the crisis and the need for radical transformation Internet searching results, if any:

[24] Brett Michington -International employer brand strategist \& author, http://www.brettminchington.com/

[25] Wikipedia-Basic

Definitions;en.wikipedia.org/wiki/Em ployerbranding

[26] Essencecomms- In this excerpt from her book, Forced Focus, Penny Burke outlines how to implement an engaging workplace brand that takes the best of an organization's external brand and applies it to an internal employer brand.

[27] How to Use Social Media as a 
Recruiting Tool.

[28] http://www.inc.com/guides/2010/04/soc ial-media- recruiting.html

[29] Changing Face of Recruitment Industry Through SocialMedia

[30] http://www.salesconex.com/2011/cha nging-face-of- recruitment-industrythrough-social-media/

[31] Recruitment Through SocialMedia, Refining Social Within Your Employer Branding Strategy to Attract, Engage \& Source Talent

[32] http://recruitsocialmedia.com/

[33] Social Media Can Drive Employee Engagement

[34] http://www.employeefactor.com/?p=2 $\underline{50}$

[35] Starbucks Uses Social Media to Drive Engagement http://www.employeefactor.com/?p=1 $\underline{273}$

[36] Berth on, P., Ewing, M., \&Hah, L.L. (2005). Captivating company: Dimensions of attractiveness in employer branding. International Journal of Advertising.

[37] Employer branding: strategic implications for staff recruitment Ralf Wilden, University of Technology, Sydney, Australia Siegfried Gudergan, University of Technology, Sydney, Australia Ian Lings, Queensland University of Technology, Australia

[38] Martin, G., Beaumont, P., Doig, R., \& Pate, J. (2005). Branding: A new performance discourse for HR?
[39] Turban, D. B. (2001). Organizational Attractiveness as an Employer on College Campuses: An Examination of the Applicant Population // Journal of Vocational Behaviour

[40] Minchington, B., Estis, R. (2009). 6 Steps to an Employer Brand Strategy // ere.net. Internet access: http://www.ere.net/2009/05/18/6stepsto-an-employer-brand-strategy/

[41] The One Thing You Must Get Right When Building a Brand by Patrick Barwise and Seán Meehan.

[42] The Brand Report card by Kevin Lane Keller: Employer Brand in India: A Strategic HR Tool for Competitive Advantage Das Tulasi V. and Rao Hanumantha P., The 11th International Research Seminar In Service Management.

\section{APA conventions}

[43] http://www.essencecomms.com.au/docs how find heart of your employerbr and.pdf

[44] http://www.businessstandard.com/india/news/companiescome-to- terms leadershipproblem/431766/

[45] http://articles.timesofindia.indiatimes. com/2011-0514/indiabusiness/29542982_1_ceosuccession- succession-planningleader

[46] http://articles.economictimes.indiatim es.com/2011-0502/news/29496261_1_successionplan-kv-kamath- infosys 
[47] http://businesstoday.intoday.in/story/h omegrown-ceo- recruitment-atkearney/1/15933.html

[48] http://articles.economictimes.indiatim es.com/2011$05-$

10/news/29528291_1_financialservices-group- ratan-tata-anil-kumarsardana

[49] http://www.articlesbase.com/educatio n-articles/

[50] http://www.infosys.com/about/whatwe- do/Pages/index.aspx

[51] http://www.infosys.com/about/who-weare/Pages/history.aspx

[52] http://www.deccanherald.com/content /162395/we- our-own-enemiesmurthy.html

[53] http://www.moneycontrol.com/news/f eatures/a-look- backwhy-infosysneeds-kv-kamath-_547102.html

[54] http://www.businessweek.com/managing /content/feb20

10/ca20100212_310794.htm

[55] http://www.tatasteel.com/corporatecitizenship/index.asp

[56] http://www.tatasteel.com/corporatecitizenship/index.asp

[57] http://www.ongcindia.com/history.asp

[58] http://www.ongcindia.com/people.asp

[59] http://www.ongcindia.com/people.asp

[60] http://www.ongcindia.com/hse.asp

[61] http://www.ongcindia.com/imd.asp

[62] http://www.belindia.com/index.aspx? $\mathrm{q}=\&$ sectionid $=$ 2

[63] http://www.belindia.com/index.aspx? $\mathrm{q}=\&$ sectionid= $\underline{3}$

[64] http://www.belindia.com/index.aspx $? \mathrm{q}=\&$ sectionid $=30$ 